\title{
Global Change and Emerging Infectious Diseases
}

\author{
Nicole Nova ${ }^{1}$, Tejas S Athni ${ }^{1}$, Marissa L Childs ${ }^{2}$, Lisa Mandle ${ }^{1,3,4}$, and Erin A Mordecai ${ }^{1}$ \\ ${ }^{1}$ Department of Biology, Stanford University \\ ${ }^{2}$ Emmett Interdisciplinary Program in Environment and Resources, Stanford University \\ ${ }^{3}$ Natural Capital Project, Stanford University \\ ${ }^{4}$ Woods Institute for the Environment, Stanford University
}

November 1, 2021

\begin{abstract}
Our world is undergoing rapid planetary changes driven by human activities, often mediated by economic incentives and resource management, affecting all life on Earth. Concurrently, many infectious diseases have recently emerged or spread into new populations. Mounting evidence suggests that global change-including climate change, land-use change, urbanization, and global movement of individuals, species, and goods-may be accelerating disease emergence by reshaping ecological systems in concert with socioeconomic factors. Here, we review insights, approaches, and mechanisms by which global change drives disease emergence from a disease ecology perspective. We aim to spur more interdisciplinary collaboration with economists and identification of more effective and sustainable interventions to prevent disease emergence. While almost all infectious diseases change in response to global change, the mechanisms and directions of these effects are system specific, requiring new, integrated approaches to disease control that recognize linkages between environmental and economic sustainability, and human and planetary health.
\end{abstract}

\section{Hosted file}

Nova_et_al_2021.pdf available at https://authorea.com/users/330225/articles/543628-globalchange-and-emerging-infectious-diseases 